\title{
A eficácia horizontal dos direitos FUndamentais no Brasil: UMa ANÁLISE SOBRE O JULGAMENTO dO RECURSO EXTRAORDINÁRIO 201.819-8 À LUZ DO CONSTITUCIONALISMO CONTEMPORÂNEO
}

The horizontal effects of fundamental rights in Brazil: a look on the judgement of the Extraordinary Appeal 201.819-8 from the contemporary constitutionalism

\section{Fernanda Graebin Mendonça}

Mestranda em Direito na Universidade Federal de Santa Maria (UFSM), Bolsista CAPES. Membro do Conselho Nacional de Pesquisa e Pós-Graduação em Direito (CONPEDI). E-mail: fernandagmendonca@gmail.com

\section{Valéria Ribas do Nascimento}

Doutora em Direito Público pela Universidade do Vale do Rio dos Sinos (UNISINOS). Professora do Programa de Pós-Graduação em Direito da UFSM. Membro do Conselho Nacional de Pesquisa e Pós-Graduação em Direito (CONPEDI) e da Associação Brasileira do Ensino do Direito (ABEDI).

CONVIDADOS

RECEBIDO EM:05/01/2016

AProvado EM:07/01/2016

DOI: $10.5585 /$ RDB.V10I5.312

"Quando protegemos os direitos humanos de todos, sem fronteiras, vivemos o dever de todos."

(Ludwig von Mises)

\section{Resumo}

O novo direito constitucional - constitucionalismo contemporâneo ou neoconstitucionalismo - surgido após o fim da Segunda Guerra Mundial é uma realidade indiscutível entre a doutrina. $\mathrm{O}$ fortalecimento e a busca pela efetividade dos direitos fundamentais é uma de suas principais bandeiras. A partir deste ideal, surgem vários fenômenos e institutos, a exemplo da eficácia horizontal dos direitos fundamentais, que consiste na produção de efeitos destes direitos não só nas relações que envolvem o poder público, mas também entre os particulares. Este trabalho tem como objetivo verificar se os ideais do neoconstitucionalismo, em especial a valorização dos 
direitos fundamentais na figura principal da eficácia horizontal destes direitos, têm se inserido nas decisões dos órgãos judiciais brasileiros, mais especificamente do Supremo Tribunal Federal, e como se pode observar esse novo movimento constitucional nas decisões judiciais. A resposta é buscada por meio da análise do julgamento do Recurso Extraordinário 201.819-8. Quanto à abordagem, o método utilizado é o dedutivo, uma vez que se parte de conceitos gerais sobre o novo direito constitucional e a eficácia horizontal dos direitos fundamentais, para, posteriormente, verificar a presença destes no caso concreto. Em segundo plano, a técnica adotada é, principalmente, a monográfica, já que se trabalha com um caso concreto. Ao final, verificouse que o julgado analisado teve a sua maioria de votos a favor do reconhecimento da eficácia horizontal, podendo-se perceber claramente, nos argumentos utilizados pelos Ministros, a aceitação e a aplicação de fenômenos do neoconstitucionalismo.

Palavras-chave: Neoconstitucionalismo. Eficácia horizontal dos direitos fundamentais. Supremo Tribunal Federal. Recurso Extraordinário 201.819-8.

\section{Abstract}

The new constitutional right - contemporary constitutionalism or neoconstitutionalism - arising after the end of World War II is an undeniable reality of the doctrine. The strengthening and the quest for effectiveness of fundamental rights is one of its main goals. From this ideal, there are various phenomena and institutes, such as the horizontal effect of fundamental rights, which is the production of effects of these rights not only in relations involving the government, but also in relations of individuals. This study aims to verify that the ideals of the neoconstitutionalism, especially the appreciation of fundamental rights in the main figure of the horizontal effectiveness of these rights, have been inserted in the decisions of the Brazilian courts, specifically the Brazilian Supreme Court, and how this new constitutional motion in judicial decisions can be observed. The answer is sought by analyzing the judgment of the Extraordinary Appeal 201.819-8. As for the approach, the method is deductive, as a part of general concepts about the new constitutional law and the horizontal effect of fundamental rights, to subsequently verify the presence of these effects in this case. In the background, the method used is mainly the monographic, since it works with a concrete case. Finally, the decision in the case had its majority voted in favor of recognition of the horizontal effect and can be seen clearly in the arguments used by the Ministers, the acceptance and application of neoconstitutionalism phenomena.

Keywords: Neoconstitutionalism. Horizontal efFects of fundamental Rights. Brazilian Supreme Court. Extraordinary Appeal 201.819-8. 
Sumário: Introdução. 1. Neoconstitucionalismo: um movimento em busca da efetividade dos direitos fundamentais. 2. A eficácia horizontal dos direitos fundamentais e o neoconstitucionalismo: uma visível interconexão. 3. O julgamento do Recurso Extraordinário 201.819-8 à luz dos ideais neoconstitucionalistas de proteção dos direitos fundamentais. Conclusão. Referências.

\section{INTRODUÇÃo}

A valorização dos direitos fundamentais a partir do protagonismo da constituição dentro de um Estado vem sendo defendida por muitos autores, com destaque para aqueles considerados "neoconstitucionalistas", ou seja, defensores do neoconstitucionalismo, ou simplesmente do novo movimento pela reconfiguração do direito constitucional $^{1}$. Os direitos fundamentais - garantias ao limite do poder do Estado - são concebidos, nesta nova mentalidade, como o principal instrumento de força normativa do diploma constitucional, expandindo a sua jurisdição e inaugurando uma nova forma de interpretá-la. Não apenas este fortalecimento dos direitos se dá no plano interno dos países, considerando que cada um deles possui uma constituição, mas é também impulsionado pela internalização e fortalecimento dos direitos humanos por meio da edição de inúmeros tratados internacionais e da criação de cortes internacionais e de sistemas regionais de proteção destes direitos.

A partir dessa vontade - e realidade - de elevar os direitos fundamentais ao ápice da realização constitucional, surgem muitas outras teses, institutos e ideias que possibilitam, em discussões mais específicas que envolvem a aplicação de direitos fundamentais, fazer exatamente isto: trazer para o caso concreto os efeitos irradiantes deste gênero de direitos. Um destes institutos é o da eficácia horizontal dos direitos fundamentais, o qual, ainda que não tenha surgido primeiro no Brasil, já é defendida por muitos estudiosos do país.

A eficácia horizontal dos direitos fundamentais, em que pese não ser também estudada sempre ao lado ou conjuntamente com o neoconstitucionalismo, possui íntimas ligações com ele: o reconhecimento da existência e da importância dos direitos fundamentais é o cerne de ambos os fenômenos surgidos a partir da metade do século XX, pois o que a eficácia horizontal justamente defende é a aplicação, a produção dos efeitos destes direitos também nas relações entre particulares, e não apenas na relação entre o poder público e o indivíduo, conforme sua formatação original. Tendo em vista que já se saber ser essa aplicável às relações privadas no Brasil, é interessante verificar se ela, bem como, e consequentemente, as ideias e frentes do neoconstitucionalismo são aceitas também nos tribunais, em especial o Supremo

1 Para aprofundar o tema, cita-se a tese de uma das autoras deste artigo. (NASCIMENTO, 2011) 
Tribunal Federal (STF), responsável maior e final pela guarda da Constituição Federal de 1988, embasando, então as decisões deste órgão.

Diante disto, pergunta-se: os ideais do neoconstitucionalismo, mais especialmente a sua bandeira principal de efetivação dos direitos fundamentais, por intermédio do instituto da eficácia horizontal destes direitos têm se inserido nas decisões dos órgãos judiciais brasileiros? Como se pode observar esse novo movimento constitucional nas decisões judiciais? A resposta para a questão não é buscada por um viés quantitativo - ou seja, por uma busca jurisprudencial de quantos julgados existem referentes ao tema da eficácia horizontal dos direitos fundamentais nos tribunais brasileiros, ou em tribunais previamente selecionados. Deste modo, foi escolhido para estudo apenas um julgado como objeto um estudo mais minucioso: a decisão do Supremo Tribunal Federal no Recurso Extraordinário (RE) 201.819-8, originário do Rio de Janeiro (RJ), pioneira no Brasil no que tange ao reconhecimento da eficácia dos direitos fundamentais nas relações particulares. Mais especificamente, são analisados os votos daqueles Ministros que se posicionaram a favor da eficácia horizontal - os Ministros Gilmar Mendes, Joaquim Barbosa e Celso de Mello. Assim, a escolha se deu pelo aspecto qualitativo, haja vista que será verificado, nos votos dos ministros e entre os seus argumentos, a existência ou não da defesa dos ideais neoconstitucionalistas, confirmando ou não a relação íntima entre a eficácia horizontal e o neoconstitucionalismo.

Quanto à abordagem, o método utilizado é o dedutivo, uma vez que se parte de conceitos gerais sobre o novo direito constitucional e a eficácia horizontal dos direitos fundamentais, apresentando-os como correntes interligadas no que tange ao alinhamento de ideais, para, ao final, verificar a presença destes ideais no caso concreto escolhido a partir da análise dos votos dos Ministros no julgamento do RE 201.819-8. Em segundo plano, a técnica adotada é, em sua maior parte, o monográfico, já que se busca conceber as concepções básicas, apresentadas nos dois primeiros capítulos, como uma lente de investigação para a análise específica do julgado eleito. $\mathrm{O}$ procedimento feito pela análise bibliográfica do tema neoconstitucionalismo e mais especificamente da eficácia horizontal dos direitos fundamentais e estudo de caso por análise jurisprudencial.

Para melhor compreensão do trabalho, ele é dividido em três capítulos: o primeiro trata sobre o novo movimento no direito constitucional, chamado comumente de neoconstitucionalismo, suas principais características e os ideais defendidos pelos autores desta corrente; o segundo apresenta a eficácia horizontal dos direitos fundamentais, instituto bastante defendido e até mesmo aceito pela jurisprudência de muitos países, fazendo-se a ligação com o neoconstitucionalismo por meio da sustentação de que ambos trazem a ideia de fortalecimento e valorização dos direitos fundamentais; e o terceiro e último capítulo faz um estudo mais detalhado do RE 201.819-8, que traz para o STF o debate sobre a eficácia dos direitos fundamentais nas relações privadas, sob a perspectiva neoconstitucionalista, apresentado 
nos capítulos anteriores.

\section{NEOCONSTITUCIONALISMO: UM MOVIMENTO EM BUSCA DA EFETIVIDADE DOS DIREITOS FUNDAMENTAIS}

Desde o surgimento das primeiras constituições, os movimentos constitucionais acompanham as suas transformações, que, por sua vez, observam as alterações que ocorrem nas sociedades, de acordo com os momentos e o contexto cultural em que estes documentos são editados. Este tipo de movimento, tradicionalmente chamado de constitucionalismo, é fruto, portanto, das mudanças que ocorrem na relação entre o Estado e o cidadão. Voltando à evolução histórica do termo, o doutrinador Alexandre de Moraes (2009, p. 1) afirma que a origem do termo relaciona-se às constituições escritas e rígidas que surgiram, primeiramente, nos Estados Unidos em 1787, e da França em 1791, esta última a partir da Revolução Francesa, apresentando dois traços marcantes: (1) a organização do Estado e (2) a limitação do seu poder, visando à proteção e à garantia de direitos. Porém, não se nega a existência de um constitucionalismo primitivo ou antigo, que antecede até mesmo as constituições em sua forma escrita.

Mesmo diante da não uniformidade quanto ao nascimento do constitucionalismo - e até mesmo de sua própria definição - o que se observa com propriedade é que ele mudou muito desde os seus primeiro resquícios, adotando as mais variadas características inclusive em um mesmo período histórico: é o que se vê nos dias atuais. Não se pode falar hoje em um constitucionalismo comum a todos os países, tendo em vista, principalmente, as diversas culturas, os vários ordenamentos jurídicos e as diferentes constituições de cada Estado, as quais devem atender às necessidades e à realidade social de cada um. Cada país tem sua própria organização e traz seu próprio rol de direitos, previsto exatamente em sua Carta Maior.

Porém, em que pese esta pluralidade, pode-se identificar hoje, principalmente após o fim da Segunda Guerra Mundial e de forma mais acentuada nas três últimas décadas, um gama de transformações ocorridas no direito constitucional - e, portanto, nas próprias constituições ao redor do mundo. A este conjunto de transformações, as quais serão melhor trabalhadas a seguir, deu-se a simples denominação de novo direito constitucional, ou, em razão da prática comum de reconfigurações de institutos a partir do surgimento de nomenclaturas com o prefixo "neo", convencionou-se chama-lo de forma mais presente de "neoconstitucionalismo"2.

2 Na visão de Miguel Carbonell, muitos autores questionam-se se haveria realmente um novo direito constitucional, ou seja, se haveria realmente algo novo no neoconstitucionalismo que justificasse a colocação do prefixo neo, ou se esta se trataria apenas de uma etiqueta vazia, que serviria para apresentação, sob uma nova roupagem, algumas questões que até então de justificavam de outra maneira. Porém, o próprio autor responde ao questionamento afirmando que, como explicação de um conjunto que busca dar conta de uma série complexa de fenômenos, pode-se dizer que o neoconstitucionalismo é algo novo dentro da 
Ainda que os novos ideais de valorização constitucional já estivessem presentes desde antes desta época, o termo "neoconstitucionalismo" surgiu na década 1990, tendo sido empregado pela primeira vez, mais especificamente, por Susanna Pozzolo, jusfilósofa, durante uma intervenção no XVIII Congresso Mundial de Filosofia Jurídica e Social em Buenos Aires e La Plata, em agosto de 1997 (MELO, 2013, p. 65). Desde então, ele tem sido bastante debatido e desenvolvido em todo o mundo, após ter se expandido pela Europa, primeiramente, até chegar aos países da América Latina, onde conta com cada vez mais adeptos e estudiosos, inclusive no Brasil. Porém, um problema em relação ao termo, mesmo diante da "crescente produção bibliográfica, resultante das discussões que vêm sendo realizadas no campo da Teoria e da Filosofia do Direito, ainda se verificam incontáveis imprecisões terminológicas e inúmeras divergências sobre o tema" (KARAM, 2013, [s.p.]).

Em breve e abrangente definição, pode-se afirmar que o neoconstitucionalismo é um movimento, principalmente teórico, de valorização do direito constitucional e da constituição, a partir de uma nova abordagem e visão do papel desta no sistema jurídico de um Estado. Este movimento busca refundar o direito constitucional a partir da teoria da força normativa deste documento e do protagonismo dos direitos fundamentais, com vistas a consolidar a ideia de um Estado constitucional, guiado e permeado pelas normas e princípios constitucionais.

Para entender como o neoconstitucionalismo surgiu e se disseminou rapidamente, Luís Roberto Barroso ([s.d.]) aponta três marcos fundamentais, de cunho histórico, filosófico e teórico. Em relação ao primeiro, o autor afirma ter o neoconstitucionalismo surgido a partir do final da Segunda Guerra Mundial na Europa, principalmente na Alemanha e na Itália e suas constituições de 1949 e 1947, respectivamente, uma vez que houve, neste período, uma reconstitucionalização deste continente a partir da aproximação das ideais constitucionalistas e com a democracia, fazendo aparecer uma nova forma de organização política, o Estado Democrático de Direito. No Brasil, o marco histórico foi o advento da Constituição de 1988, também em um contexto de reconstitucionalização do país após um período de mais de vinte anos de ditadura, passando este diploma "da desimportância ao apogeu em menos de uma geração" (BARROSO, [s.d]), com a revelação de um sentimento constitucional ${ }^{3}$.

No que toca ao segundo marco, o filosófico, ele remete a um novo ideal constitucional baseada no pós-positivismo, na forma da complementariedade das

teoria e da prática do Estado constitucional de Direito. (CARBONELL, 2007, p. 9)

3 Sobre a Constituição de 1988 como marco do neoconstitucionalismo no Brasil, Janaína Reckziegel e Roni Fabro também observam: "A partir da tendência desenhada de alteração para o viés da vida do indivíduo como um todo, no contexto da satisfação de seus legítimos interesses e de acordo com as peculiaridades locais, verifica-se que a Constituição da República Federativa do Brasil de 1988, que inaugurou um novo tempo na política do País, alterou sensivelmente o ordenamento jurídico, haja vista que privilegiou a vida e a dignidade humana, valorizando a realização humana e abandonando o individualismo exagerado." (RECKZIEGEL; FABRO, 2014, p. 166) 
correntes positivista e jusnaturalista, reaproximando, então, direito e moral. Finalmente, quanto ao marco teórico, apresentam-se três grandes transformações que se coadunam com os planos anteriores: a) a força normativa da constituição, atribuindo a ela o status de norma jurídica, dotada de imperatividade; b) a expansão da jurisdição constitucional, que consolida a supremacia da constituição, destacando-se o surgimento de cortes constitucionais e modelos de controle de constitucionalidade; e c) a nova interpretação constitucional como modalidade de interpretação jurídica, aplicando-se à interpretação constitucional elementos tradicionais de interpretação do direito, lembrando que ela não derroga o modelo tradicional, mas apenas atende e dá eficácia às normas constitucionais, por meio de uma reconfiguração do papel da norma e do papel do juiz ${ }^{4}$.

Desta forma, pode-se resumir este novo direito constitucional como focado na constituição, colocando-a como parâmetro de todo o ordenamento jurídico:

Este espaço passa a ser ocupado por uma Constituição intensamente invasora, que impregna e condiciona a legislação, a jurisprudência, os operadores do Direito em geral e também os mais diversos atores políticos. O Constitucionalismo contemporâneo passa a transformar os valores e opções políticas fundamentais em normas jurídicas, num grau de hierarquia ou centralidade diferenciado em relação às demais normas do sistema e que, portanto, as condiciona. (ROSSI, 2008, p. 3806)

Contudo, há que se ressaltar que, em razão da variedade de constituições e teorias constitucionais atinentes aos Estados em suas especificidades, o neoconstitucionalismo não é uma corrente única e fechada. A partir do novo conceito de

4 "A interpretação jurídica tradicional desenvolveu-se sobre duas grandes premissas: (i) quanto ao papel da norma, cabe a ela oferecer, no seu relato abstrato, a solução para os problemas jurídicos; (ii) quanto ao papel do juiz, cabe a ele identificar, no ordenamento jurídico, a norma aplicável ao problema a ser resolvido, revelando a solução nela contida. Vale dizer: a resposta para os problemas está integralmente no sistema jurídico e o intérprete desempenha uma função técnica de conhecimento, de formulação de juízos de fato. No modelo convencional, as normas são percebidas como regras, enunciados descritivos de condutas a serem seguidas, aplicáveis mediante subsunção22.Com o avanço do direito constitucional, as premissas ideológicassobre as quais se erigiu o sistema de interpretação tradicional deixaram de ser integralmente satisfatórias. Assim: (i) quanto ao papel da norma, verificou-se que asolução dos problemas jurídicos nem sempre se encontra no relato abstrato do texto normativo. Muitas vezes só é possível produzir a resposta constitucionalmente adequada à luz do problema, dos fatos relevantes, analisados topicamente; (ii) quantoao papel do juiz, já não lhe caberá apenas uma função de conhecimento técnico, voltado para revelar a solução contida no enunciado normativo. $O$ intérprete torna-seco-participante do processo de criação do Direito, completando o trabalho do legislador, ao fazer valorações de sentido para as cláusulas abertas e ao realizar escolhas entre soluções possíveis." (BARROSO, [s.d.]) 
direito constitucional surgido de maneira geral a partir de meados do século XX são feitas várias interpretações e adaptações de significados. Assim, o conceito de neoconstitucionalismo trata-se, portanto, de um essentially contested concept (conceito essencialmente contestado, em português), em razão da abrangência e variedade de significados que assumiu o termo, em cujo âmbito se inserem doutrinas que têm e tiveram vários perfis teóricos e filosóficos (MELO, 2013, p. 62), e também em função de diferentes contextos históricos e culturais em que encontraram aplicação. Portanto, percebe-se que o termo "neoconstitucionalismo" não designa uma corrente unitária de pensamento, e sim várias correntes e uma série de tendências comuns, motivo pelo qual, inclusive, o constitucionalista mexicano Miguel Carbonell nomeou a obra por ele organizada sobre o tema de "Neoconstitucionalismo(s)" (cf. CARBONELL, 2013).

De qualquer forma, existem características comuns a todas as teses neoconstitucionalistas, que permitem afirmar tratar-se de um movimento que vem ocorrendo em todo o mundo, revolucionando a forma de conceber e constituição. Pode-se destacar, inclusive observando os marcos já expostos, as seguintes: a materialidade da constituição, com um denso conteúdo substantivo; o protagonismo dos juízes na garantia e proteção da constituição como seus intérpretes; a onipresença da constituição, ou seja, os direitos fundamentais por ela garantidos irradiam para todo o sistema jurídico e regulam toda a legislação; e o estabelecimento pela constituição de uma regulação baseada em princípios; a aplicação do princípio da ponderação em caso de colisão de princípios constitucionais, que ganham novo valor e importância (SANCHÍS, 2007, p. 213-235).

A materialidade da constituição tem como consequência básica conceber as normas constitucionais, e principalmente os direitos nela contidos "como normas supremas, efectiva y diretamente vinculantes, que pueden y deben ser observadas en toda operación de interpretación y aplicación del derecho [...]"5 (SANCHÍS, 2007, p. 216). Tal assertiva vale especialmente para os direitos fundamentais previstos neste diploma, haja vista serem nela incorporados, como objetivo mais primário, para limitar o poder do Estado sobre o indivíduo, garantindo a eles direitos básicos que asseguram a sua dignidade como pessoa humana. Neste mesmo sentido, então, considerando que a Constituição produz normas jurídicas, uma vez que é dotada de juridicidade, os seus efeitos se propagam para o restante do ordenamento jurídico do qual a Constituição é o maior expoente (RECKZIEGEL; FABRO, 2014, p. 169)

Ainda nas palavras de Luís Prieto Sanchís, "los derechos fundamentales [...] exhiben una extraordinária fuerza expansiva que inunda, impregna o irradia sobre el conjunto del sistema [...]"6 $(2007$, p. 216), o que remete a outra característi-

5 Tradução livre das autoras: "Como normas supremas, efetivas e diretamente vinculantes, que podem e devem ser observadas em toda operação de interpretação e aplicação do direito [...]."

6 Tradução livre das autoras: "os direitos fundamentais exibem uma extraordinária força 
ca deste novo direito constitucional, qual seja, a onipresença da constituição. Esta onipresença é confirmada pelo fato de a constituição, por ser uma carta ampla de direitos, recheada de princípios que permitem interpretações para os mais diversos e diferentes casos, e então não existiria problema que não pudesse ser constitucionalizado, ou seja, que não pudesse ter sua resposta buscada nas normas e preceitos constitucionais. Segunda Carlos Bernal Pulido (2009, p. 80)a constituição seria material porque dotada de denso conteúdo substantivo, com normas que não estabelecem apenas como o Estado deve ser organizar e adotar suas decisões, mas também inclui o que ele pode e o que ele deve decidir.

O protagonismo dos juízes também caracteriza as teses neoconstitucionalistas, pois são eles que devem proteger e garantir a aplicação da constituição e de suas normas. Ressalte-se que esta encomenda aos juízes não é apenas aos membros dos tribunais constitucionais, e sim de todo e qualquer juiz com jurisdição no território do Estado, que deve observar, nos casos concretos, o respeito aos preceitos constitucionais, em especial os seus princípios, os quais permitem que este diploma possa "falar com muitas vozes" - considerando que os princípios são mais abertos que as regras - e podem assegurar principalmente os direitos fundamentais em vários casos que chegam a este juízes. Daniel Sarmento, nesta monta, afirma que cresceu muito a importância política do Poder Judiciário, e cada vez mais "questões polêmicas e relevantes para a sociedade passaram a ser decididas por magistrados, e sobretudo por cortes constitucionais, muitas vezes em razão de ações propostas pelo grupo político ou social que fora perdedor na arena legislativa" (SARMENTO, 2009, [s.d.]).

Ainda, os autores neoconstitucionalistas igualmente defendem uma constituição principialista, ou seja, uma constituição que fornece razões justificativas diferentes e tendencialmente contraditórias, e isto vale tanto para o legislador quanto para o juiz, os quais são chamados a conjugar estas razões e alcançar um ponto ótimo e de recíproca satisfação, ou, quando menos, a evitar que nenhuma delas reste anulada ou postergada, e isso pelo simples fato de que todas as razões são constitucionais (SANCHÍS, 2007). Deste modo, tem-se que a mudança constitucional é no sentido de abertura da constituição para os valores, estes na forma de princípios, os quais invadem todo o ordenamento jurídico, dando-lhe fundamento constitucional, o qual deve ser de atenção do juiz. Para o neoconstitucionalismo, o juiz, garantidor da Lei Maior do país, deve buscar interpretar a norma constitucional e retirar dela direitos (ou deveres) sem especificar suas colisões e nem as condições de precedência de uns sobre os outros. Este mandamento aponta para outro elemento importante a ser destacado nessa trilha de mudanças, que é a aplicação da constituição pelo método da ponderação.

expansiva que inunda, impregna ou irradia sobre o conjunto do sistema [...]."

7 A expressão é utilizada por Luís Prieto Sanchís, indicando a natureza aberta da constituição principialista ou substantiva, defendida pelos autores deste movimento do novo direito constitucional (cf. SANCHÍs, 2007). 
A ponderação é uma forma de argumentação pela qual se constrói uma hierarquia móvel (não definitiva erga omnes) entre os princípios constitucionais que entram em colisão, devendo o intérprete, no caso concreto e atentando para as suas especificidades, dizer qual deles deve prevalecer. O sentido da ferramenta da ponderação tem como função oferecer uma forma de "argumentación plausible cuando nos hallamos en presencia de razones justificatorias del mismo valor y tendencialmente contradictorias, algo que suele ocurrir con frecuencia en el ámbito de los derechos fundamentales" "SANCHÍS, 2007). Neste sentido, aponta Daniel Sarmento:

Como boa parcela das normas mais relevantes destas constituições caracteriza-se pela abertura e indeterminação semânticas - são, em grande parte, princípios e não regras - a sua aplicação direta pelo Poder Judiciário importou na adoção de novas técnicas e estilos hermenêuticos, ao lado da tradicional subsunção. A necessidade de resolver tensões entre princípios constitucionais colidentes - freqüente em constituições compromissórias, marcadas pela riqueza e pelo pluralismo axiológico - deu espaço ao desenvolvimento da técnica da ponderação, e tornou freqüente o recurso ao princípio da proporcionalidade na esfera judicial. (SARMENTO, 2009, [s.p.])

Também, em harmonia com as demais características do neoconstitucionalismo já apresentadas, cita-se a estruturação e aplicação de um modelo argumentativo, afastando o modelo geográfico que antes predominava: nesta, há um claro limite entre a constituição e a legislação, sabendo-se exatamente onde termina um e começa o outro, ou seja, quando o caso concreto trata de norma legal e quando trata de norma constitucional. Já naquele modelo, por sua vez, este limite é quase invisível, e a relação entre os blocos de normas são bastante intensas, misturando-se conteúdo legal com conteúdo constitucional. Justamente porque, conforme se viu, a constituição passa a permear as regras jurídicas abaixo dela e também todas as relações jurídicas, em razão de sua abertura, e essa irradiação se dá principalmente por meio dos direitos fundamentais. Assim,

no existe un derecho general, definitivo y concluyente, pero sí existe lo que pudiera llamarse un derecho a la argumentación, un derecho a que la conducta sea enjuiciada como el ejercicio de un derecho en conflicto con otros derechos o bienes constitucionales, cuyo resultado, como ya se ha dicho, queda librado al juicio de ponderación. (SANCHÍS, 2007, p. 225) ${ }^{9}$

8 Tradução livre das autoras: "argumentação plausível quando nos encontramos na presença de razões justificativas do mesmo valor e tendencialmente contraditórias, algo que só ocorre com frequência no âmbito dos direitos fundamentais."

9 Tradução livre das autoras: "não existe um direito geral, definitivo e concludente, mas sim existe o que se pode chamar de um direito à argumentação, um direito a que a conduta seja 
Deste modo, fica claro que os ideais neoconstitucionalistas quebram com muitos dos modelos positivistas que predominavam no início do século XX, trazendo uma revalorização da constituição como diploma provido de normas imperativas e que aproximam o direito da moral ao reconhecer a força normativa de princípios revestidos de forte carga axiológica (a exemplo do valor maior, o da dignidade da pessoa humana). É a partir daí que os direitos fundamentais ganham mais força e se tornam o principal instrumento da jurisdição constitucional, inclusive abrindo espaço para debates e teses que defendem a sua eficácia até mesmo nas relações privadas (lembra-se que os direitos fundamentais são normas de direito público e tem como função principal proteger o indivíduo do poder estatal, garantindo-lhe mínima dignidade), o que culminou no instituto da "eficácia horizontal dos direitos fundamental”, o qual será abordado no tópico seguinte.

\section{A EFICÁCIA HORIZONTAL DOS DIREITOS FUNDAMENTAIS E O NEOCONSTITUCIONALISMO: UMA VISÍVEL INTERCONEXÃO}

A eficácia entre particulares dos direitos fundamentais (segundo a terminologia da doutrina alemã, a Drittwirkung) é um dos temas mais polêmicos e interessantes da atual dogmática do direito constitucional. Isto porque as liberdades constitucionais foram originalmente concebidas como garantias frentes ao Estado, aos poderes públicos, e se mostra um desafio para os tribunais constitucionais, especialmente, desafiar dogmas do ideal liberal que são pilares do Estado de Direito - ao menos em sua concepção clássica - aplicando às relações particulares a proteção de direitos fundamentais (ESTRADA, 2007, p. 121). Antonio Enrique Pérez-Luño (2010, p. 18-19) salienta que, ao se tratar das principais posturas teóricas sobre a interpretação dos direitos fundamentais, percebe-se que para as teses positivistas, identificadas com o Estado de Direito na sua versão liberal, estes direitos não são aplicados a terceiros, uma vez que se constituem garantias de defesa com o Estado. Contudo, segue o autor afirmando que para aquelas que têm como suporte o Estado Social de Direito, que se baseia na teoria dos valores, estes direito são dotados de eficácia erga omnes, visto que plenamente aplicáveis no seio das relações entre particulares.

Apenas para consolidar o tema sobre um terreno seguro, há que se trazer aqui, primeiramente, no que consistem os direitos fundamentais, ainda que já tenha sido possível compreende-los a partir do que já foi exposto. De acordo com o entendimento de Ingo Sarlet (2012, p. 29), é importante mencionar que os direitos fundamentais diferenciam-se dos direitos humanos por se aplicarem àqueles direito do ser humanos específicos que foram reconhecidos e positivados na esfera do direito

processada como o exercício de um direito em conflito com outros direitos ou bens constitucionais, cujo resultado, como foi dito, é entregue ao juízo de ponderação." 
constitucional positivo de cada Estado, ou seja, que foram considerados, para aquele Estado, como um direito que deve ser fundamental à manutenção e garanta da dignidade da pessoa humana de cada um. Assim, os direitos fundamentais "constituem o conjunto de direitos e liberdades institucionalmente reconhecidos e garantidos pelo direito positivo de determinado Estado" (SARLET, 2012, p. 31), sendo, portanto, delimitados espacial e temporalmente, e não deixando de serem direitos efetivamente humanos, de cunho jusnaturalista, nascidos com o objetivo de proteger o indivíduo do poder do Estado.

A partir disso, percebe-se de forma cristalina que os direitos fundamentais possuem como função original a proteção contra o poder público; não havendo que se falar, em sua forma primeira, na sua eficácia entre relações particulares, que não envolvessem o Estado, uma vez que estas relações, inclusive, são pautadas pela máxima autonomia da vontade das partes que se relacionam. Porém, com o surgimento de novos ideais constitucionais a partir da metade do século XX, por meio do denominado neoconstitucionalismo, houve uma intensa valorização dos direitos fundamentais como instrumentos de salvaguarda constitucional, além do que, como se viu, houve uma invasão por parte das constituições nos ordenamentos jurídicos e dos outros ramos do direito, em especial do direito civil e de todos os institutos e relações por ele regidos.

Assim, fazendo uma releitura do constitucionalismo liberal clássico e social democrático, o neoconstitucionalismo trouxe como seu ponto mais alto o princípio da dignidade da pessoa humana e novos paradigmas para a ordem jurídica constitucional, podendo-se destacar: o desenvolvimento da teoria dos direitos fundamentais, com características multifuncionais, os quais possuem força normativa direta e são exigentes de aplicação em máxima efetividade; a constitucionalização dos direitos, com a elevação de questões de interesse público ao status constitucional em contrapartida à irradiação dos valores constitucionais sobre todo o ordenamento jurídico; e a jurisdição constitucional, atribuindo-se aos tribunais constitucionais surgidos a partir da Segunda Guerra Mundial - a missão de legítimo intérprete da constituição (FARIA, 2013).

Observou-se, então, a partir da desigualdade fática, a possibilidade de violação de direitos fundamentais também nas relações entre particulares, e, via reflexa, da dignidade humana, seu objeto de proteção, e a intangibilidade da autonomia privada, instituto clássico do direito civil, cedeu espaço à força normativa dos direitos fundamentais, agora com eficácia também horizontal (FARIA, 2013). Neste mesmo sentido, assinala André Rufino do Vale:

[...] é fato notório que, na sociedade neocapitalista, essa igualdade formal não supõe uma igualdade material, e que nela o pleno desfrute dos direitos fundamentais se encontra, em muitas ocasiões, ameaçado pela existência, na esfera privada, de centros de poder não menos importantes que os que 
correspondem aos órgãos públicos. (VALE, 2004, p. 100)

Considerou-se, consoante se observa, que as relações particulares, apesar de serem regidas pela autonomia da vontade, privada, também podem dar ensejo a violações de direitos fundamentais, e a não tutela estatal nestes casos consistiria em uma esvaziamento da função precípua destes direitos, que é, em primeiro lugar, garantir a dignidade da pessoa humana. Com base nisso, Ingo Sarlet advoga com propriedade sobre esta extensão desta eficácia dos direitos: "a liberdade individual não apenas carece de proteção contra os Poderes públicos, mas também contra os mais fortes no âmbito da sociedade, [...] os detentores de poder social e econômico, já que é nesta esfera que as liberdades se encontram particularmente ameaçadas" (SARLET, 2012, p. 386).

A perspectiva neoconstitucionalista de atenção aos direitos fundamentais contribuiu de forma decisiva para esta mudança de pensamento em relação à sua eficácia, levando à compreensão de que a centralidade assumida por este gênero de direito na constituição exige uma interpretação diferenciada dos mesmos. Assim, noções como a de eficácia privada ou horizontal destes direitos, a proibição do retrocesso social, a maximização ou efetividade, a restringibilidade excepcional, e a projeção positiva, são características que devem ser tomadas em conta na compreensão, interpretação e aplicação daqueles direitos (ROSSI, 2008, p. 3818). É neste contexto que assume importância a dimensão objetiva dos direitos fundamentais, a qual "decorre que do reconhecimento de que os direitos fundamentais condensam os valores mais relevantes para determinada comunidade política" (SARMENTO, 2004, p. 134-135), e como garantia destes valores morais, este gênero de direitos não é um problema estatal apenas, mas de toda esta comunidade.

A aplicação dos direito fundamentais nas relações privadas, a partir dessa percepção dos direitos fundamentais como ápice do conteúdo constitucional, passa a ser um tema em discussão na doutrina e na jurisprudência em muitos países; ele tem se desenvolvido sob os títulos "eficácia privada", "eficácia externa", "eficácia em relação a terceiros" ou "horizontal dos direitos fundamentais", em especial e de forma mais profunda e disseminada na doutrina e na jurisprudencial constitucional alemão da segunda metade do século XX (SARLET, 2012, p. 383). A ideia principal desta teoria é a de que, ainda que a autonomia privada conceda liberdade e poder de pactuar amplamente regras conforme o interesse individual no âmbito do direito privado, ela não pode estar desconexa aos direitos fundamentais e à dignidade da pessoa humana (FACHIN, 2012).

Com isso, ao Estado, não cabe apenas e tão somente a função de reconhecer este rol de direitos na sua formalidade, mas se mostra imprescindível que o Estado atue de forma a concretizar tais direitos, impondo a obrigação de cumprimento a ele próprio e a todos sob sua jurisdição, sob pena de responder por eventual ofensa. As razões que conduziram, historicamente, à proclamação dos direitos fundamentais 
podem, então, justificar que eles sejam também aplicados às relações particulares, sendo este o argumento trazido por Jean Rivero (citado por Paulo Gustavo Gonet Branco), o qual "repele a coexistência, que tacha de esquizofrênica, de duas éticas diferentes, conforme o Estado apareça, ou não, como ator na relação jurídica" (BRANCO, 2002, p. 2).

Parece un contrasentido, por ejemplo, que el reconocimiento del derecho fundamental a la libertad de expresión por la normativa constitucional pudiera ver reducida su aplicación a la exigencia de que el Estado permita la libre difusión de opiniones, pero consintiera las presiones sobre la libertad de pensamiento e ideas o la prohibición de manifestarlas, ejercitada por un empresario en relación con sus asalariados..$^{10}$ (PÉREZ-LUÑO, 2004, p. 23)

É interessante notar a lição de Paulo Gustavo Gonet Branco (2002, p. 3): ele lembra que, também no plano internacional, que também na esfera do direito internacional, vem se firmando o princípio de que os direitos humanos não somente vinculamos Estados negativamente, impedindo-os de afetar os bens protegidos, como, por igual, criam para eles obrigações de agir em defesa desses bens, a exemplo do caso $X$ e Y versus Holanda ${ }^{11}$, de 1985, no qual o Tribunal Europeu de Direitos Humanos não hesitou em proclamar que os Estados estavam obrigados a adotar medidas destinadas a garantir o respeito à vida privada, mesmo na esfera das relações dos indivíduos entre si.

Uma vez admitida a eficácia horizontal dos direitos fundamentais, há discussão no âmbito doutrinário sobre se essa eficácia seria imediata, ou seja, aplicável de pronto, sendo os particulares submetidos, de forma direta e necessária, ao sistema constitucional de direitos e liberdades, ou se ela seria de eficácia mediata, dependendo de prévia atuação dos poderes públicos ao cumprir o mandato constitucional de configurar a situação jurídica dos particulares de acordo com os direitos fundamentais (PÉREZ-LUÑO, 2010, p. 319). Estas teses são predominantes no direito germânico - pelos juristas e pela corte constitucional daquele país - e no direito espanhol e português, respectivamente (SARMENTO, 2004, p. 238 e 246). Ou seja, não existe ainda uma decisão clara e uniforme sobre a verdadeira eficácia dos direi-

10 Tradução livre das autoras: "Parece um contrassenso, por exemplo, que o reconhecimento do direito fundamental à liberdade de expressão pela normativa constitucional possa ver reduzida sua aplicação à exigência de que o Estado permita a livre difusão de opiniões, mas consinta as pressões sobre a liberdade de pensamento ou ideais ou a proibição de manifestá-las, exercitada por um empresário em relação com seus empregados."

110 inteiro teor da decisão do caso referido - que originalmente tem como título case of $X$ and $Y v$. the Netherlands - pode ser encontrado no endereço $<$ http://hudoc.echr.coe.int/sites/eng/pages/search.aspx?i=001-57603\#\{“itemid":[“001-57603”] $\}>$, em língua inglesa. 
tos fundamentas na seara privada, dependendo muito da aceitação de cada doutrina nos diferentes sistemas jurídicos dos Estados. O que impende destacar é que, de uma forma ou de outra, a eficácia horizontal destes direitos já ganha espaço em muitos países, não sendo uma realidade diferente no Brasil.

No que tange, então, à situação brasileira nesta temática, Rodrigo Martins Faria $^{12}$ é enfático ao esclarecer que, em que pese ter acolhido muitos dos ideais do novo direito constitucional iniciado antes de seu advento, a "vanguardista Constituição Federal de 1988 adotou substancialmente a teoria dos direitos fundamentais e o paradigma da jurisdição constitucional, faces do neoconstitucionalismo, sem expressa alusão sobre a eficácia dos direitos fundamentais" (FARIA, 2013, [s.p.]). Contudo, o desenvolvimento desta tese já é significativo, ainda que não exista, também aqui, uma consistente e conclusiva dogmática relativamente a esta discussão. Existem algumas decisões isoladas que permitem concluir pela aceitação, por parte do Supremo Tribunal Federal brasileiro, da eficácia horizontal dos direitos fundamentais.

O precedente RE $158.215^{13}$, da Segunda Turma do STF, publicado em 07 de junho de 1996, afasta a jurisprudência da linha de entendimento que preconiza a necessidade de uma relação entre Estado e indivíduo, para que se possam invocar direitos fundamentais, não aderindo à posição dos que conferem decisivo significado ao fato de tais direitos terem sido concebidos, originalmente, como garantias dos indivíduos contra as expansões dos poderes públicos, inteligência esta dominante

12 Neste mesmo sentido, Ingo Wolfgang Sarlet (2012, p. 385).

130 recurso trata de um caso da expulsão de membro de uma cooperativa sem o atendimento da garantia do contraditório e da ampla defesa no âmago do devido processo legal. Segue a ementa da decisão: "DEFESA - DEVIDO PROCESSO LEGAL - INCISO LV DO ROL DAS GARANTIAS CONSTITUCIONAIS - EXAME - LEGISLAÇÃO COMUM. A intangibilidade do preceito constitucional assegurador do devido processo legal direciona ao exame da legislação comum. Daí a insubsistência da óptica segundo a qual a violência à Carta Política da República, suficiente a ensejar o conhecimento de extraordinário, há de ser direta e frontal. Caso a caso, compete ao Supremo Tribunal Federal exercer crivo sobre a matéria, distinguindo os recursos protelatórios daqueles em que versada, com procedência, a transgressão a texto constitucional, muito embora torne-se necessário, até mesmo, partir-se do que previsto na legislação comum. Entendimento diverso implica relegar à inocuidade dois princípios básicos em um Estado Democrático de Direito - o da legalidade e do devido processo legal, com a garantia da ampla defesa, sempre a pressuporem a consideração de normas estritamente legais. COOPERATIVA - EXCLUSÃO DE ASSOCIADO - CARÁTER PUNITIVO - DEVIDO PROCESSO LEGAL. Na hipótese de exclusão de associado decorrente de conduta contrária aos estatutos, impõe-se a observância ao devido processo legal, viabilizado o exercício amplo da defesa. Simples desafio do associado à assembléia geral, no que toca à exclusão, não é de molde a atrair adoção de processo sumário. Observância obrigatória do próprio estatuto da cooperativa." (RE n 158.215-RS, Rel. Min. Marco Aurélio, DJ de 07/06/1996)" (SUPREMO TRIBUNAL FEDERAL, 1996). 
nos Estados Unidos, ainda que com os temperamentos da doutrina do state action (BRANCO, 2012, p. 2). Porém, ainda que esta decisão mereça referência, o mais importante caso apreciado pela corte constitucional brasileira, na qual esta entrou de forma mais profunda na temática da eficácia horizontal, foi o julgamento do RE 201.819-8, o qual contou com brilhantes explanações dos Ministros aplicadas ao caso concreto. As minúcias deste caso serão analisadas a seguir.

\section{O JULGAMENTO DO RECURSO EXTRAORDINÁRIO 201.819-8 À LUZ DOS IDEAIS NEOCONSTITUCIONALISTAS DE PROTEÇÃO DOS DIREI- TOS FUNDAMENTAIS}

ORecurso Extraordinário 201.819-8 éum caso emblemático e paradigmático no que tange ao tema da eficácia horizontal dos direitos fundamentais. $\mathrm{O}$ recurso, interposto pelo réu do processo original, a União Brasileira de Compositores (UBC) contra a decisão do Tribunal de Justiça do Rio de Janeiro que denegou o seu recurso anterior, julgando nula a expulsão de um compositor associado à UBC, sob o argumento de que esta havia, ao exclui-lo, violado o princípio e a garantia constitucional do devido processo legal.

Para buscar decisão favorável a ela, a associação afirmou que seguiu rigorosamente as previsões do seu estatuto sobre o procedimento de exclusão de um associado. Porém, conforme já havia observado o julgador a quo, para além do adequado cumprimento de suas regras estatutárias, "o direito defesa do autor foi mesmo violado, sem que se adentre no mérito, na justiça ou injustiça da punição" (SUPREMO TRIBUNAL FEDERAL, 2006), pois, de acordo com o Tribunal de Justiça do Rio de Janeiro, observadas as infrações, autor da ação original "tinha que ser, expressa e formalmente, cientificado das mesmas e convocado a apresentar, querendo, em prazo razoável, a sua defesa, facultando-lhe a produção das provas que entendesse cabíveis" (SUPREMO TRIBUNAL FEDERAL, 2006).

O julgamento do recurso teve início em 11 de outubro de 2006, pela Segunda Turma do STF, ora composta pelos Ministros Ellen Gracie, Joaquim Barbosa, Gilmar Mendes, Carlos Velloso e Celso de Mello, e tendo como relatora originária a Ministra Ellen Gracie, enquanto que para relatar o acórdão, foi escolhido o Ministro Gilmar Mendes. A ementa do acórdão foi editada da seguinte forma:

SOCIEDADE CIVIL SEM FINS LUCRATIVOS. UNIÃO BRASILEIRA DE COMPOSITORES. EXCLUSÃO DE SÓCIO SEM GARANTIA DA AMPLA DEFESA E DO CONTRADITÓRIO. EFICÁCIA DOS DIREITOS FUNDAMENTAIS NAS RELAÇÕES PRIVADAS. RECURSO DESPROVIDO. I. EFICÁCIA DOS DIREITOS FUNDAMENTAIS NAS RELAÇÕES PRIVADAS. As violações a direitos fundamentais não ocorrem somente no âmbito das relações entre o cidadão e o Estado, mas 
igualmente nas relações travadas entre pessoas físicas e jurídicas de direito privado. Assim, os direitos fundamentais assegurados pela Constituição vinculam diretamente não apenas os poderes públicos, estando direcionados também à proteção dos particulares em face dos poderes privados. II. OS PRINCÍPIOS CONSTITUCIONAIS COMO LIMITES À AUTONOMIA PRIVADA DAS ASSOCIAÇÕES. A ordem jurídico-constitucional brasileira não conferiu a qualquer associação civil a possibilidade de agir à revelia dos princípios inscritos nas leis e, em especial, dos postulados que têm por fundamento direto o próprio texto da Constituição da República, notadamente em tema de proteção às liberdades e garantias fundamentais. $\mathrm{O}$ espaço de autonomia privada garantido pela Constituição às associações não está imune à incidência dos princípios constitucionais que asseguram o respeito aos direitos fundamentais de seus associados. A autonomia privada, que encontra claras limitações de ordem jurídica, não pode ser exercida em detrimento ou com desrespeito aos direitos e garantias de terceiros, especialmente aqueles positivados em sede constitucional, pois a autonomia da vontade não confere aos particulares, no domínio de sua incidência e atuação, o poder de transgredir ou de ignorar as restrições postas e definidas pela própria Constituição, cuja eficácia e força normativa também se impõem, aos particulares, no âmbito de suas relações privadas, em tema de liberdades fundamentais. III. SOCIEDADE CIVIL SEM FINS LUCRATIVOS. ENTIDADE QUE INTEGRA ESPAÇO PÚBLICO, AINDA QUE NÃO-ESTATAL. ATIVIDADE DE CARÁTER PÚBLICO. EXCLUSÃO DE SÓCIO SEM GARANTIA DO DEVIDO PROCESSO LEGAL.APLICAÇÃO DIRETA DOS DIREITOS FUNDAMENTAIS À AMPLA DEFESA E AO CONTRADITÓRIO. As associações privadas que exercem função predominante em determinado âmbito econômico e/ ou social, mantendo seus associados em relações de dependência econômica e/ou social, integram o que se pode denominar de espaço público, ainda que não-estatal. A União Brasileira de Compositores - UBC, sociedade civil sem fins lucrativos, integra a estrutura do ECAD e, portanto, assume posição privilegiada para determinar a extensão do gozo e fruição dos direitos autorais de seus associados. A exclusão de sócio do quadro social da UBC, sem qualquer garantia de ampla defesa, do contraditório, ou do devido processo constitucional, onera consideravelmente o recorrido, o qual fica impossibilitado de perceber os direitos autorais relativos à execução de suas obras. A vedação das garantias constitucionais do devido processo legal acaba por restringir a própria liberdade de exercício profissional do sócio. O caráter público da atividade exercida pela sociedade e a dependência do vínculo associativo para o exercício profissional de seus sócios legitimam, no caso concreto, a aplicação direta dos direitos fundamentais 
concernentes ao devido processo legal, ao contraditório e à ampla defesa (art. 5\%, LIV e LV, CF/88). IV. RECURSO EXTRAORDINÁRIO DESPROVIDO. (SUPREMO TRIBUNAL FEDERAL, 2006)

Já pela leitura da ementa, já se percebe a presença do viés neoconstitucionalistas no julgamento, especialmente em razão da confirmação, logo no início da ementa, do julgamento em desfavor do recorrido, ou seja, em favor da aplicação da eficácia horizontal dos direitos fundamentais. Ressalte-se, nenhum dos Ministros nem mesmo o Ministro Gilmar Mendes nem o Ministro Joaquim Barbosa, que se posicionaram favor da aplicação dos direitos fundamentais no presente caso - menciona expressamente e confessa se filiar, neste julgamento, à tese do neoconstitucionalismo. Isso não é exigido e nem havia a expectativa, nessa análise, de se constatar tal fato. Porém, o que se pretende é, analisando os argumentos em favor da eficácia horizontal no julgamento, quais deles - e quais passagens - remetem aos ideais neoconstitucionalistas, como, por exemplo, prevalência e valorização dos princípios, valorização do papel do juiz etc., com base nas características do neoconstitucionalismo já expostas anteriormente no trabalho.

No decorrer do julgamento, a relatora Ministra Ellen Gracie posicionou-se a favor da associação recorrente, afirmando que, na verdade, não há qualquer ilegalidade ou desrespeito à Constituição ou aos direitos fundamentais no presente caso, uma vez que "a controvérsia envolvendo a exclusão de um sócio de entidade privada resolve-se a partir das regras do estatuto social e da legislação civil em vigor" (SUPREMO TRIBUNAL FEDERAL, 2006). Assim, ela conclui que não houve qualquer ofensa ao princípio da ampla defesa, pois foram obedecidas as regras de exclusão fixadas no estatuto, o qual se entende aceito pelo recorrido em razão de sua livre adesão à associação. Portanto, o que se vê do voto da relatora é que ela não concebe os direitos fundamentais (como o direito ao devido processo legal e à ampla defesa, no caso em análise) como dotados de eficácia entre particulares.

Após a prolação do voto da Ministra, o Ministro relator para o acórdão Gilmar Mendes pediu vistas do processo para melhor analisá-lo, vez que, frisou, o caso se tratava de um típico da aplicação de direitos fundamentais às relações privadas. Ao iniciar o seu voto, Gilmar Mendes comenta a atual e relevante discussão da doutrina e da jurisprudência acerca da matéria nos países da Europa e nos Estados Unidos. Inclusive, colaciona longos trechos de sua obra "Direitos Fundamentais: Eficácia das garantias constitucionais nas relações privadas - análise da jurisprudência da Corte Constitucional Alemã", no qual ele faz um estudo sobre casos concretos julgados pelo tribunal constitucional alemão, ilustrando a discussão jurisprudencial mencionada por ele. Em seguida, afirma que o tema também tem sido objeto de estudo de vários doutrinadores ${ }^{14}$ no Brasil, bem como alguns casos já foram analisados

14 "Com base nas raras ocasiões em que a Corte se debruçou sobre o tema, é possível delinear os contornos que a aplicação dos direitos fundamentais nas relações entre privadas pode assumir. (cf. 
pelo Supremo Tribunal Federal, embora em raras ocasiões.

O Ministro Gilmar Mendes traz alguns exemplos de julgados em que se discutiu a aplicabilidade de direitos fundamentais em relações de caráter particular: o RE 160.222/, do Rio de Janeiro, publicado em 01/09/1995; o RE 158.215, do Rio Grande do Sul, publicado em 07/06/1996 e julgado também pela Segunda Turma; e o RE 161.243/, oriundo do Distrito Federal, publicado em 19/12/1997. Todos eles foram julgados reconhecendo-se a eficácia do direito fundamental aplicável ao caso em relações particulares, o que leva o Ministro a afirmar que, considerando o caso concreto em julgamento - ainda que ele possua suas especificidades - "o Supremo Tribunal Federal já possui histórico identificável de uma jurisdição constitucional voltada para a aplicação desses direitos às relações privadas" (SUPREMO TRIBUNAL FEDERAL, 2006).

Voltando-se especificamenteao caso do recurso interposto pela UBC, o Ministro Gilmar Mendes ressalta que esta associação é integrante da estrutura do Escritório Central de Arrecadação e Distribuição (ECAD), o qual possibilita que os seus associados possam perceber os direitos autorais de suas obras ${ }^{15}$, sendo "incontroverso que, no caso, ao restringir as possibilidades de defesa do recorrido, elaassume posição privilegiada para determinar, preponderantemente, a extensão do gozo e fruição dos direitos autorais de seu associado" (SUPREMO TRIBUNAL FEDERAL, 2006). Ou seja, o papel da UBC teria como função integrar aquilo que se poderia chamar de espaço público, ainda que não estatal, e esta natureza, este caráter público da atividade realizada pela entidade "parece decisivo aqui para legitimar a aplicação direta dos direitos fundamentais concernentes ao devido processo legal, ao contraditório e à ampla defesa (art. $5^{\circ}$, LIV e LV, da CF) ao processo de exclusão de sócio de entidade" (SUPREMO TRIBUNAL FEDERAL, 2006). Conforme assinala o Ministro,

\begin{abstract}
SARMENTO, Daniel. Direitos Fundamentais e Relações Privadas. Rio de Janeiro: Lumen luris, 2004; SOMBRA, Thiago. A eficácia dos direitos fundamentais nas relações jurídico-privadas: A identificação do contrato como ponto de encontro dos direitos fundamentais. Sérgio Antônio Fabris Ed. Porto Alegre: 2004; VALE, André Rufino do. Eficácia dos direitos fundamentais nas relações privadas. Sérgio Antônio Fabris Ed. Porto Alegre: 2004; KAUFMANN, Rodrigo. Dimensões e Perspectivas da Eficácia Horizontal dos Direitos Fundamentais. Possibilidades e limites de aplicação no Direito Constitucional Brasileiro. Tese para a obtenção do título de Mestre em Direito apresentada em 2004 e orientada pelo Professor José Carlos Moreira Alves; BRANCO, Paulo Gustavo Gonet. Associações, Expulsão de Sócios e Direitos Fundamentais, Direito Público v. 1, no 2 (out. /dez. 2003) Porto Alegre: Síntese; Brasília: Instituto Brasiliense de Direito Público, 2003, pp. 170-174; e SARLET, Ingo Wolfgang. A Eficácia dos Direitos Fundamentais. Porto Alegre: Livraria do Advogado, 1998)." (SUPREMO TRIBUNAL FEDERAL, 2006)
\end{abstract}

15 O Ministro Gilmar Mendes afirma que o ECAD até mesmo poderia se configurar como um serviço público por delegação legislativa, sendo o único ente que possibilitaria a gestão coletiva de arrecadeção e distribuição de direitos autorais, podendo o titular destes direitos apenas fazê-lo através de entidade associada ao ECAD, trazendo como embasamento o voto do Ministro Sepúlveda Pertence no julgamento da ADI n².054/DF. 
Essa realidade deve ser enfatizada principalmente porque, para os casos em que o único meio de subsistência dos associados seja a percepção dos valores pecuniários relativos aos direitos autorais que derivem de suas composições, a vedação das garantias constitucionais de defesa pode acabar por lhes restringir a própria liberdade de exercício profissional.

Logo, as penalidades impostas pela recorrente ao recorrido, extrapolam, em muito, a liberdade do direito de associação e, sobretudo, o de defesa. Conclusivamente, é imperiosa a observância das garantias constitucionais do devido processo legal, do contraditório e da ampla defesa (art. $5^{\circ}$, LIV e LV, da CF). (SUPREMO TRIBUNAL FEDERAL, 2006).

O Ministro Joaquim Barbosa, cujo voto seguiu-se ao do colega Gilmar Mendes, também opinou pela improcedência do recurso. Em seu voto, ele sustentou que a aplicabilidade dos direitos fundamentais na seara privada é consequência da prática jurídica contemporânea, sendo um dos fatores desta a superação da barreira que separava, antes, o direito público do privado. Além dele, o Ministro chama a atenção pra os efeitos de um sistema que tem como característica uma jurisdição constitucional:

Por outro lado, um fenômeno facilmente observável em sistemas jurídicos dotados de jurisdição constitucional - a chamada "constitucionalização do direito privado", mais especificamente do direito civil. Noutras palavras, as relações privadas, aquelas que há até bem pouco tempo se regiam exclusivamente pelo direito civil, hoje sofrem o influxo dos princípios de direito público, emanados predominantemente das decisões proferidas pelos órgãos de jurisdição constitucional. (SUPREMO TRIBUNAL FEDERAL, 2006)

Ato contínuo, Joaquim Barbosa afirma que outro efeito da aceitação quase que universal da "supremacia da Constituição e da jurisdição constitucional como instrumento destinado a assegurá-la reside no fato de que os direitos fundamentais [...], não mais se concebem como limitações impostas única e exclusivamente ao Estado" (SUPREMO TRIBUNAL FEDERAL, 2006). Após trazer á baila alguns trechos de obras de doutrinadores reconhecidos na temática da eficácia horizontal dos direitos fundamentais, e referir que a tendência para reconhecê-la vem ocorrendo também na Europa, ele observa que a "força irradiadora e vinculante da Constituição demorou a se fazer sentir, sobretudo na Europa, onde por longo tempo prevaleceu a ideia da Constituição como mero documento político, sem força jurídica imediata" (SUPREMO TRIBUNAL FEDERAL, 2006).

Em seguida, o Ministro Carlos Velloso acompanhou a relatora, não reconhecendo a eficácia horizontal do direito fundamental no caso concreto. A prolação do voto do Ministro Celso de Mello seguiu-se a do voto de Carlos Velloso, tendo este opinado no sentido de negar provimento ao recurso da UBC, sem que, porém, tenha 
trazido nenhum argumento novo, cingindo-se a acompanhar o voto dos colegas Ministros Joaquim Barbosa e Gilmar Mendes. Pode-se destacar, apenas o passagem na qual o membro do STF Celso de Mello afirma que "não é por outro motivo que o novo Código Civil brasileiro, em alguns de seus preceitos [...] expressamente proclama a necessária submissão das entidades civis às normas que compõem o estatuto constitucional das liberdades e garantias fundamentais [...]."'(SUPREMO TRIBUNAL FEDERAL, 2006), trazendo, a título exemplificativo, o art. $57^{16}$ do Código Civil, o qual se aplica de forma adequado ao conflito em análise. Após este último voto, houve o encerramento do julgamento, negando-se, portanto, seguimento ao recurso interposto pela associação civil, reconhecendo-se a eficácia do direito fundamental à ampla defesa na relação privada entre o autor original da ação e a UBC, em favor daquele.

A partir dessa análise, com foco especial no embasamento dos votos dos Ministros Gilmar Mendes e Joaquim Barbosa, por terem sustentado de forma mais expressa a aplicabilidade dos direitos fundamentais nas relações privadas e em especial no caso concreto, pode perceber que se está diante temas da dogmática jurídica que ainda exigem maior equacionamento por parte da doutrina e também da jurisprudência brasileiras, principalmente do STF, restando clara a indefinição do posicionamento quanto ao novo perfil das associações civis, bem como à falta de parâmetros balizadores da extensão aos particulares dos direitos fundamentais, que permitam aferir sua utilização atentando-se à segurança jurídica, autonomia privada, separação dos poderes, entre outros valores constitucionais em jogo (IWAKIRI, 2008, p. 61).

Porém, em que pesa a necessidade do tema sobre a eficácia horizontal dos direitos fundamentais ser maior consolidada em especial na jurisprudência da corte constitucional brasileira, o julgamento do RE 201.819-8 traz alguns ensinamentos e argumentos interessantes em favor desse instituto a eficácia horizontal de modo geral, que transcendem as especificidades do caso e ilustram o fortalecimento e a onipresença das normas constitucionais, em especial dos direitos fundamentais, ideal maior das teses neoconstitucionalistas. Assim, pode-se verificar as características do movimento do novo direito constitucional nos argumentos dos Ministros. E, de forma incontestável, a valorização dos direitos fundamentais - possivelmente a maior bandeira defendida pelo neoconstitucionalismo - está presente ao longo do julgamento do recurso nos argumentos utilizados pelos Ministros em favor do reconhecimento da eficácia destes direitos na relação privada em questão.

Em relação a uma de suas características mais marcantes, o protagonismo dos juízes como guardiães da constituição, ela pode ser percebida a partir do próprio fato deste caso concreto ter chegado ao STF para ser solucionado. Ainda que, consoante se viu, a Constituição Federal seja diploma cujas normas devem ser

16 Diz o art. 57 do Código Civil: “A exclusão do associado só é admissível havendo justa causa, assim reconhecida em procedimento que assegure direito de defesa e de recurso, nos termos previstos no estatuto." 
observadas e garantidas por todos os juízes do território nacional, a chegado do RE 201.819-8 (e de outros casos semelhantes de eficácia horizontal dos direitos fundamentais, inclusive citados pelos Ministros em seus votos) ao STF indica que a salvaguarda da Lei Maior dos Estados por parte dos juízes vem crescendo, exatamente ao passo que os ideais neconstitucionalistas vêm ganhando força doutrinária e jurisprudencialmente no Brasil. Este protagonismo nos juízes como protetores das normas constitucionais está intrinsecamente relacionado com outros dois elementos neoconstitucionais: o denso conteúdo material e a onipresença da constituição, a qual cada vez mais permeia todo o ordenamento jurídico brasileiro, conforme as palavras do próprio Ministro Joaquim Barbosa ao tratar da "constitucionalização do direito privado", em especial o direito civil, por meio da observância da jurisdição constitucional e da "força irradiadora e vinculante da Constituição". Foi com base neste fator que a Segunda Turma decidiu que a UBC deveria, ainda que em uma relação privada com umex-membro, respeitar o princípio e a garantia da ampla defesa e do devido processo legal.

Em relação a estes dois princípios, também é possível observa uma das frentes defendidas pelos neoconstitucionalistas: a prevalência dos princípios constitucionais sobre as regras. No julgamento do presente recurso o princípio da ampla defesa, do contraditório e do devido processo legal sobrepuseram-se a qualquer outra regra de direito civil - calcada na autonomia da vontade, regra máxima dos contratos entre particulares - e até mesmo à regra constante do estatuto da UBC, a qual foi devidamente observada quando da exclusão do associado recorrido, pois sequer houve controvérsia quando à observância das regras estatutárias, conforme salientou a própria Ministra Ellen Gracie, que votou a favor da recorrente UBC. Tal entendimento foi perfeitamente de acordo com o que Paulo Gustavo Gonet Branco leciona sobre o tema, quando afirma que um direito fundamental apontado "como de incidência no âmbito dos relacionamentos privados é o direito de ampla defesa [...que] é tido como de observância obrigatória, em se tratando de exclusão de sócio ou de membro de associação particular" (BRANCO, 2002, [s.p.]). Deste modo, foi com base na predominância destes dois princípios (verdadeiras garantias) ligados diretamente aos direitos fundamentais que o recorrido teve reconhecida a nulidade da decisão de sua exclusão, feita com base nas regras do estatuto, mas contrariando preceitos constitucionais maiores.

Também, outra importante característica dos ideais neoconstitucionalistas é justamente a aplicação do modelo argumentativo neste julgamento. Atentando-se para a discussão dos Ministros sobre se os direitos fundamentais seriam aplicáveis à relação privada - regida por leis infraconstitucionais - sob análise, percebe-se que os argumentos favoráveis à eficácia horizontal denotam uma quase ausência de limites entre estes direitos e a lei. Explica-se melhor: no caso estudado, prevaleceu o argumento de que não se pode separar claramente a lei e os direitos fundamentais, uma vez que estes últimos acabam por permear - e orientar - os preceitos legais, e 
o conteúdo da Constituição Federal, aqui, acaba por permear o conteúdo das leis, ao contrário do método. Fica claro, também neste ponto, a onipresença do diploma constitucional.

Portanto, tem-se que os argumentos utilizados pelos Ministros que opinaram a favor do recorrido no recurso em tela retratam claramente, aplicados ao caso concreto, por óbvio - ideais deste novo direito constitucional que ganham força (ainda maior) na doutrina e cada vez mais na jurisprudência, em especial na do Supremo Tribunal Federal. Ainda que a palavra "neoconstitucionalismo" não tenha sido proferida por nenhum dos membros da Corte durante o julgamento, percebe-se a mudança da interpretação da Constituição Federal com base em uma jurisdição e uma nova interpretação constitucional, o que se coaduna perfeitamente com os marcos teóricos apontados por Luís Roberto Barroso, anteriormente mencionados. Assim, resta claro que o gradual e frequente reconhecimento da eficácia horizontal dos direitos fundamentais é consequência direta deste novo movimento no direito constitucional hoje e, razão pela qual a valorização e o respeito aos direitos fundamentais observados nos julgamentos do STF - e dos demais tribunais - é o maior exemplo da força que este movimento ganha na jurisprudência brasileira.

\section{CONCLUSÃO}

Conclui-se, pelo presente trabalho, que a jurisprudência brasileira, tendo por base os julgamentos do STF e em especial o RE 201.819-8, apresenta-se receptivo à tese da eficácia horizontal dos direitos fundamentais, cuja natureza está intrinsecamente ligada aos ideais neoconstitucionalistas, de supremacia da constituição e dos direitos fundamentais nela elencados. Inclusive, os argumentos apresentados pelos Ministros que sustentaram a eficácia destes direitos na relação particular sub judice - ou seja, aqueles que opinaram pelo não provimento do recurso interposto pela associação UBC - são bastante enfáticos ao defender o fortalecimento da jurisdição e uma nova interpretação constitucional, características do movimento do novo direito constitucional.

Assim, o RE 201.819-8 é um dos exemplos mais claros de que a eficácia dos direitos fundamentais às relações privadas é uma tese surgida a partir - ou juntamente - com a ideia de proteção deste gênero de direitos sustentada pelos autores neoconstitucionalistas. A necessidade latente que estes direitos devem ser respeitados a partir de uma atribuição de força imperativa e de onipresença das normas constitucionais, principalmente aqueles que trazem direitos aos indivíduos e garantem o princípio maior da dignidade da pessoa humana, vem sendo percebida pelas cortes constitucionais de vários países, as quais, como guardiãs das constituições por meio da atuação de seus juízes, atualizam suas decisões harmoniosamente com estes novos ideais surgidos a partir da metade do século XX na Europa, e com o advento da Constituição Federal de 1988 no Brasil. 
Em que pese a dificuldade que novas e ousadas correntes enfrentam para se consolidar na jurisprudência de cortes mais tradicionais, vislumbra-se no Brasil, por meio do STF, uma tendência para os novos preceitos espalhados pelo novo direito constitucional que se fortalece por meio de institutos como a eficácia horizontal nas relações privadas. E este é um fator positivo, pois esta tendência aponta para a cada vez maior efetivação de direitos em seu conceito e abrangência mais amplo, tornando-se a mais alta corte do país um exemplo que deve inspirar todos os demais juízes - também guardiães da Lei Maior - na longa empreitada rumo à garantia da dignidade da pessoa humana para todos, em qualquer situação.

\section{REFERÊNCIAS}

BARROSO, Luís Roberto. Neoconstitucionalismo e constitucionalização do direito. Disponível em: <http://www.luisrobertobarroso.com.br/wp-content/themes/LRB/ pdf/neoconstitucionalismo_e_constitucionalizacao_do_direito_pt.pdf $>$. Acesso em: 05 jan. 2016.

BRANCO, Paulo Gustavo Gonet. Associações, expulsão de sócios e direitos fundamentais. Revista Diálogo Jurídico. Salvador, CAJ - Centro de Atualização Jurídica, n. 13, abril/maio, 2002. Disponível em: <http://www.direitopublico.com. br/PDF_13/DIALOGO-JURIDICO-13-ABRIL-MAIO-2002-PAULO-GUSTAVOGONET.pdf>. Acesso em: 05 jan. 2016.

CARBONELL, Miguel (org.). Neoconstitucionalismo(s). Madrid: Trotta, 2003.

. El constitucionalismo em su laberinto. In: CARBONELL, Miguel (ed.). Teoría del neoconstitucionalismo - ensayos escogidos. Madrid: Trotta, 2007, p. 9-12.

ESTRADA, Alexei Julio. Los tribunales constitucionales y la eficácia entre particulares de los derechos fundamentales. In: CARBONELL, Miguel (ed.). Teoría del neoconstitucionalismo - ensayos escogidos. Madrid: Trotta, 2007, p. 121-157.

FACHIN, ZulmarAntonio; BENHOSSI, Karina Pereira. A importância da eficácia horizontal como garantia da preservação dos direitos fundamentais e da dignidade da pessoa humana. In: CONPEDI/UFF. Direitos Fundamentais e Democracia I. Florianópolis, FUNJAB, 2012, p. 374-404.

FARIA, Rodrigo Martins. A eficácia horizontal dos direitos fundamentais no plano processual das relações privadas e a jurisprudência do Supremo Tribunal Federal após a Constituição Federal de 1988. Artigos do TJMG, 67. ed., 8 de janeiro de 2013. Disponível em: <http://www.tjmg.jus.br/data/files/1B/02/3C/58/D9F1C31081DB91C3180808FF/A\%20efic_cia\%20horizontal\%20dos\%20direitos..jan.2013.pdf>. Acesso em: 04 jan. 2016.

IWAKIRI, William Tetsuo Teixeira. $R E n^{\circ}$ 201.819-8/RJ: a eficácia horizontal dos 
direitos fundamentais e sua aplicação no âmbito das associações civis. 2008. $77 \mathrm{f}$. Monografia (Graduação em Direito) - Universidade Federal do Paraná, Curitiba, 2008.

MELO, Milena Petters. As recentes evoluções do constitucionalismo na América Latina: neoconstitucionalismo? In: WOLKMER, Antonio Carlos; MELO, Milena Petters (org.). Constitucionalismo latino-americano: tendências contemporâneas. Curitiba: Juruá, 2013, p. 59-87.

MORAES, Alexandre de. Direito constitucional. 24. ed. São Paulo: Atlas, 2009.

NASCIMENTO, Valéria Ribas do. O tempo das reconfigurações do constitucionalismo. Por uma cultura constitucional cosmopolita. São Paulo: LTr, 2011.

PÉREZ-LUÑO, Antonio Enrique. Derechos humanos, estado de derecho y constitución. 10. ed. Madrid: Tecnos, 2010.

. Los derechos fundamentales. 8. ed. Madrid: Tecnos, 2004.

PULIDO, Carlos Bernal. El neoconstitucionalismo y la normatividade del derecho. Bogotá: Universidad Externado de Colombia, 2009.

RECKZIEGEL, Janaína; FABRO, Roni Edson. Autonomia da vontade e autonomia privada no sistema jurídico brasileiro. Revista de Direito Brasileira, ano 4, v. 8, mai.-ago. 2014, p. 161-177. Disponível em: <http://www.rdb.org.br/ojs/index.php/ revistadireitobrasileira/article/view/286/142>. Acesso em: 05 jan. 2016.

ROSSI, Amélia Sampaio. Neoconstitucionalismo e direitos fundamentais. In: XVII Encontro Preparatório para Congresso Nacional do CONPEDI. Anais... Florianópolis: Fundação Boiteux, 2008, p. 3802-3822. Disponível em: $<$ http://www.conpedi.org.br/manaus/arquivos/anais/salvador/amelia_do_carmo_sampaio_rossi.pdf $>$. Acesso em: 05 jan. 2016.

SANCHÍS, Luis Prieto. El constitucionalismo de los derechos. In: CARBONELL, Miguel. Teoría del neoconstitucionalismo: ensayos escogidos. Madrid: Trotta, 2007, p. 213-235.

SARLET, Ingo Wolfgang. A eficácia dos direitos fundamentais: uma teoria geral dos direitos fundamentais na perspectiva constitucional. 11. ed. Porto Alegre: Livraria do Advogado, 2012.

SARMENTO, Daniel. Direitos fundamentais e relações privadas. Rio de Janeiro: Lumen Juris, 2004.

. O neoconstitucionalismo no Brasil: riscos e possibilidades. Revista Brasileira de Estudos Constitucionais. Belo Horizonte, v. 3, n. 9, p. 95-133, jan./mar. 2009. Disponível em: <https://direitoesubjetividade.files.wordpress.com/2010/08/danielsarmento-o-neoconstitucionalismo-no-brasill.doc>. Acesso em: 04 jan. 2016. 
SUPREMO TRIBUNAL FEDERAL. Julgamento do Recurso Extraordinário $n^{\circ}$ 201.819-8/RJ. Recorrente: União Brasileira de Compositores (UBC). Recorrido: Arthur Rodrigues Villarinho. Relatora Ministra Ellen Gracie. Brasília/DF, 11 de outubro de 2006. Publicado em 27 de outubro de 2006.

. Julgamento do Recurso Extraordinário $n^{\circ}$ 158.215/RS. Recorrente: Ayrton Da Silva Capaverde e outros. Recorrido: Cooperativa Mista São Luiz Ltda. Relator Ministro Marco Aurélio Mello. Brasília/DF, 30 de abril de 1996. Publicado em 07 de junho de 1996.

TRINDADE, André Karam. Crítica à impressão da expressão neoconstitucionalismo. Consultor Jurídico, 19 de janeiro de 2013. Disponível em: <http://www.conjur. com.br/2013-jan-19/diario-classe-critica-imprecisao-expressao-neoconstitucionalismo>. Acesso em: 07 set. 2014>. Acesso em: 05 jan. 2016.

VALE, André Rufino do. A eficácia dos direitos fundamentais nas relações privadas. Porto Alegre: Sérgio Antônio Fabris, 2004. 